\title{
Seasonal Association of Immune Thrombocytopenia in Adults
}

\author{
Anıl Tombak ${ }^{1}$, Burcu Boztepe ${ }^{2}$, Naci Tiftik ${ }^{1}$, Melda Cömert ${ }^{3}$, Ozan Salim${ }^{4}$ Kaniye Aydın \\ Emel Gürkan ${ }^{6}$, Orhan Kemal Yücel ${ }^{4}$, Güray Saydam ${ }^{3}$, Mehmet Ali Sungur ${ }^{7}$
}

\author{
${ }^{1}$ Department of Hematology, Mersin University Faculty of Medicine, Mersin, Turkey \\ ${ }^{2}$ Department of Internal Medicine, Mersin University Faculty of Medicine, Mersin, Turkey \\ ${ }^{3}$ Department of Hematology, Ege University Faculty of Medicine, İzmir, Turkey \\ ${ }^{4}$ Department of Hematology, Akdeniz University Faculty of Medicine, Antalya, Turkey \\ ${ }^{5}$ Department of Internal Medicine, Çukurova University Faculty of Medicine, Adana, Turkey \\ ${ }^{6}$ Department of Hematology, Çukurova University Faculty of Medicine, Adana, Turkey \\ ${ }^{7}$ Department of Biostatistics, Düzce University Faculty of Medicine, Düzce, Turkey
}

Background: Immune thrombocytopenia (ITP) is an autoimmune disorder. It is characterized by thrombocytopenia due to thrombocyte destruction mediated by autoantibodies; however, cytotoxic and defective regulatory T-lymphocytes play an important role in its pathogenesis. While childhood ITP is usually acute, self-limiting and generally seasonal in nature, ITP in adults is usually chronic; its relation with seasons has not been studied.

Aims: We investigated whether months and/or seasons have triggering roles in adults with ITP.

Study Design: Descriptive study.

Methods: A retrospective case review of adult patients with primary ITP diagnosed at various University Hospitals in cities where Mediterranean climate is seen was performed. Demographic data, date of referral and treatments were recorded. Corticosteroid-resistant, chronic and refractory cases were determined. Relation between sex, corticosteroid-resistant, chronic and refractory ITP with the seasons was also investigated.

Results: The study included 165 patients (124 female, mean age $=42.8 \pm 16.6$ ). Most cases of primary ITP were diagnosed in the spring $(p=0.015)$. Rates of patients diagnosed according to the seasons were as follows: $35.8 \%$ in spring, $23 \%$ in summer, $20.6 \%$ in fall, and $20.6 \%$ in winter. With respect to months, the majority of cases occurred in May (18.2\%). Time of diagnosis according to the seasons did not differ between genders $(\mathrm{p}=0.699)$. First-line treatment was corticosteroids in $97.3 \%$, but $35 \%$ of the cases were corticosteroid-resistant. Steroid-resistant patients were mostly diagnosed in the spring $(52.1 \%)(\mathrm{p}=0.001)$. ITP was chronic in $52.7 \%$ of the patients and they were also diagnosed mostly in the spring $(62.7 \%)(\mathrm{p}=0.149)$.

Conclusion: This is the first study showing seasonal association of ITP in adults and we have observed that ITP in adults is mostly diagnosed in the spring. The reason why more patients are diagnosed in the spring may be due to the existence of atmospheric pollens reaching maximum levels in the spring in places where a Mediterranean climate is seen.

Keywords: Allergens, immune thrombocytopenia, pollen, seasons 
Immune thrombocytopenia (ITP) is an autoimmune disorder. It is characterized by isolated thrombocytopenia due to accelerated thrombocyte destruction and impaired thrombocyte production. Its incidence is approximately $1.6-3.9$ per 100,000 person/years in adults (1-4). Autoantibodies against platelet surface glycoproteins play major roles in both impaired thrombocyte production and thrombocyte destruction. Cytotoxic T-lymphocytes are also involved in the pathophysiology of ITP. Therefore, ITP pathogenesis involves a complex network of systemic events including interactions between B and T-lymphocytes and inflammatory cytokines (5). ITP may be primary or in association with other disorders (secondary). Secondary causes include viral infections (including human immunodeficiency virus, hepatitis $\mathrm{C}$ ), certain drugs and autoimmune diseases (particularly antiphospholipid antibody syndrome) (6). According to the International Working Group (IWG), primary ITP is defined as a thrombocyte count less than $100 \times 10^{9} / \mathrm{L}$ in the absence of other causes, which can be associated with thrombocytopenia (7). The IWG also defines ITP as newly diagnosed (diagnosis to 3 months), persistent (3 to 12 months from diagnosis) or chronic (lasting for more than 12 months) (7). Severe ITP is defined as the presence of bleeding symptoms requiring treatment or new bleeding requiring additional therapeutics with a different agent or an increased dose, while refractory ITP is defined as the presence of severe primary ITP following splenectomy (7).

Immune thrombocytopenia in children is usually acute and generally seasonal in nature; it is often seen in winter and fall, suggesting that infectious or environmental agents like viral infections and vaccination (especially measles, mumps, rubella vaccine) may trigger the immune system to produce autoantibodies against platelets (8). Watch and wait is appropriate for many children with no or only minor bleeding symptoms and intravenous immunoglobulin (IVIG) (Baxter, Lessines, Belgium) or a short course of corticosteroids is used as first-line treatment if therapy is needed $(7,9)$. In comparison, adult primary ITP often has an insidious onset with no obvious trigger and follows a more chronic course (10). Adults with a thrombocyte count $<30 \times 10^{9} / \mathrm{L}$ should be treated for ITP and corticosteroids or IVIG is used as first line treatment (9).

In this study, we investigated whether the months and/or seasons have triggering roles in newly diagnosed adult patients with ITP; this is the first study investigating the relation of ITP in adults with the seasons.

\section{MATERIALS AND METHODS}

In this retrospective study, adults with primary ITP who were diagnosed at various University Hospitals located within the Mediterranean region of Turkey between 2006 and 2014 were included. Demographic data and date of referral were all recorded. Patients were categorized according to the season of referral period. In addition, the treatments were recorded, and corticosteroid-resistant, chronic and refractory ITP cases were determined. We also investigated whether there was a relation between sex, corticosteroid-resistant, chronic and refractory ITP with the seasons. This study was approved by the local Ethics Committee of Mersin University Faculty of Medicine and written informed consent was obtained from the study participants.

\section{Statistical analysis}

Chi-square or Likelihood ratio tests were used for analyzing associations between categorical variables. Comparisons between groups were performed using One-Way ANOVA for continuous variables. Statistical analyses were performed by PASW (Predictive Analytics Software is a registered trademark of SPSS Inc., Chicago, IL, USA) v.18 statistical package and $p$ values less than 0.05 were considered statistically significant.

\section{RESULTS}

Within the study period, a total of 165 patients with newly diagnosed primary ITP were included in the study (124 female and 41 male cases, median age $42.8 \pm 16.6$ years). Most cases of primary ITP were diagnosed in the spring $(\mathrm{p}=0.015)$. Ratios of patients diagnosed according to the seasons were as follows: $35.8 \%$ in spring $(n=59), 23 \%$ in summer $(n=38), 20.6 \%$ in fall $(\mathrm{n}=34), 20.6 \%$ in winter $(\mathrm{n}=34)$ (Figure 1). With respect to months, the majority of cases occurred in May $(18.2 \%$, $\mathrm{n}=30$ ) (Figure 2). The time period of diagnosis according to the seasons did not differ between genders $(\mathrm{p}=0.699)$. In addition, when we divided the patients into 3 groups according to their ages as follows, $<30$ years $(\mathrm{n}=49), 31-60$ years $(\mathrm{n}=89)$ and $>60$ years $(\mathrm{n}=27)$, the time period of diagnosis according to the seasons in the 3 age groups also did not differ between genders $(\mathrm{p}=0.248)$.

First line treatment was corticosteroids in $97.3 \%$ and IVIG in $2.7 \%$ of cases. Thirty five percent of cases $(n=47)$ were corticosteroid-resistant and there was no difference in terms of steroid resistance according to gender $(\mathrm{p}=0.373)$. Steroidresistant patients were also mostly diagnosed in the spring. Rates were as follows: $52.1 \%$ in spring $(\mathrm{n}=25), 14.3 \%$ in summer $(\mathrm{n}=5), 42.9 \%$ in fall $(\mathrm{n}=12)$ and $20 \%$ in winter $(\mathrm{n}=5)$ $(\mathrm{p}=0.001)$ (Figure 3).

Immune thrombocytopenia was chronic in $52.7 \%(\mathrm{n}=87)$ of the patients and the rate of chronic ITP was higher in women than in men $(57.3 \%$ versus $39 \%)(p=0.043)$. Patients with chronic ITP were also diagnosed mostly in the spring $(62.7 \%, \mathrm{n}=37)$; 


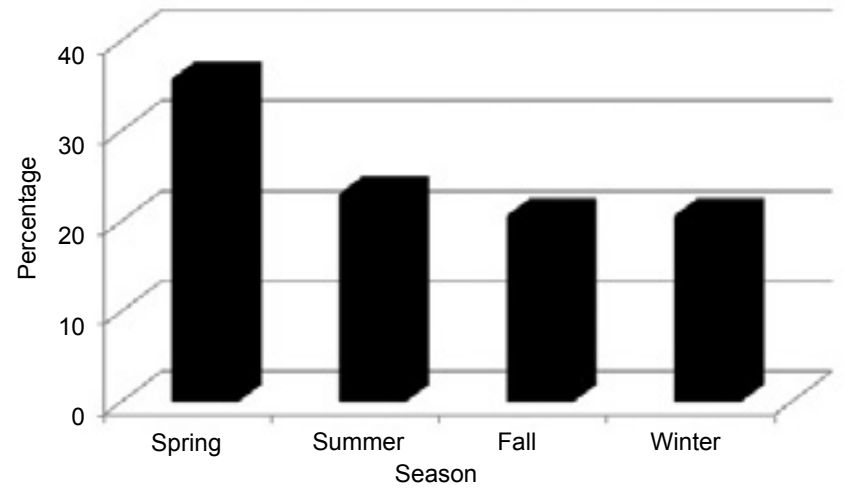

FIG. 1. Seasonal variation of adults with immune thrombocytopenia

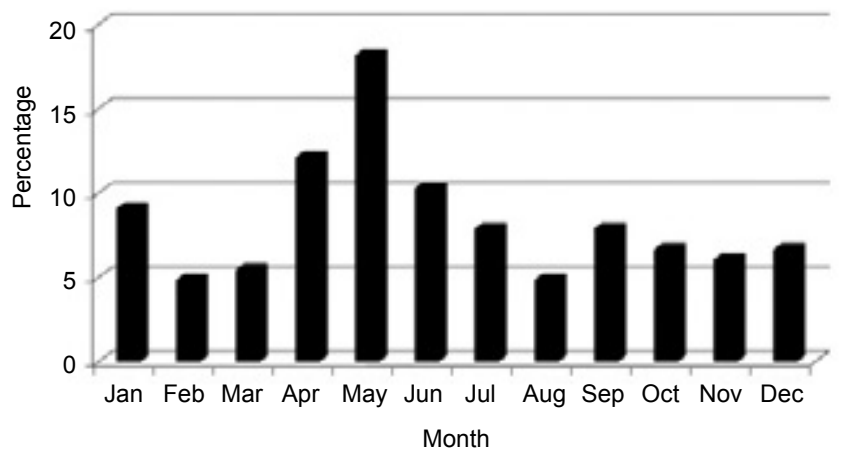

FIG. 2. Monthly distribution of adults with immune thrombocytopenia

however, this result was not statistically significant $(\mathrm{p}=0.149)$. Fifty percent $(\mathrm{n}=19)$ of chronic ITP cases were diagnosed in the summer, $52.9 \%(\mathrm{n}=18)$ in the fall and $38.2 \%(\mathrm{n}=13)$ in the winter (Figure 4).

Ten patients had refractory ITP and the time of diagnosis did not differ according to the seasons in these patients (4 patients were diagnosed in spring, 4 in summer, 1 in fall, and 1 in winter $)(\mathrm{p}=0.462)$.

\section{DISCUSSION}

In this retrospective study, we observed that ITP in adults is mostly diagnosed in the spring, especially in May, and this is the first study to show the seasonal association of primary ITP in adults. We have also seen that the corticosteroid-resistant and chronic ITP cases were also diagnosed mostly in spring.

In children, seasonal variations of ITP were shown in a few studies, but the results were not compatible with each other. Zeller and colleagues showed that most childhood ITP cases occurred during winter months (11). In another study performed by Hafiz et al. (12), childhood ITP was mostly diagnosed during the summer and at least in the winter. The first study was performed in Nordic countries where the climate is

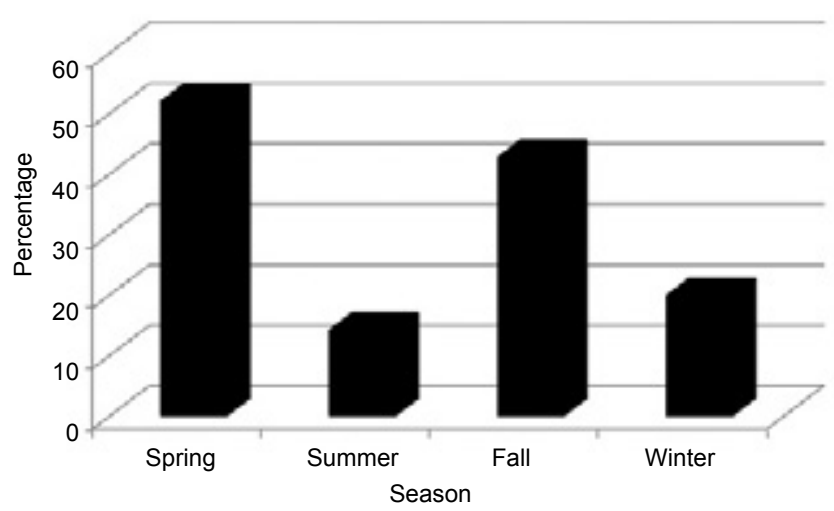

FIG. 3. Seasonal variation of steroid-resistant adults with immune thrombocytopenia

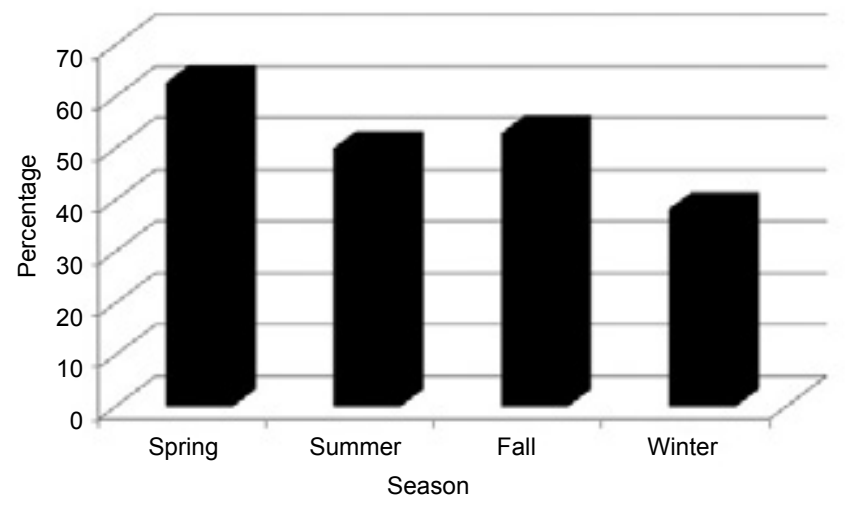

FIG. 4. Seasonal variation of adults with chronic immune thrombocytopenia characterized by short, cool summers and long, cold winters. The second study was performed in Bangladesh where a tropical climate exists. A recent study from France searching the epidemiology of incident ITP showed that incidence varied cyclically in the year, with a peak in January and nadir in the summer for both in adults and children (13). However, this study included not only cases with primary ITP, but also those with secondary ITP. The researchers also found that there is a gradient of incidence in mainland France and a lower incidence in overseas French departments, independent of age, gender, and population density. The authors explained this difference of geographically different incidence of ITP as a possible role of unknown environmental factors in ITP pathogenesis. In children, the seasonal variations can be explained by specific infections and vaccinations; two thirds of the patients experience flu-like fever during the weeks preceding ITP onset (14). The role of the influenza virus has been suspected for a long time (14). It could play a direct role in the ITP pathogenesis by promoting antiplatelet-antibodies production and/ or decreasing platelet production (13). The pathogenic role of influenza vaccine is also debated, particularly in older patients 
(15-18). However, the climate may play a role in the pathogenesis of ITP; there might be an unrecognized environmental factor related to the weather conditions that may cause a certain physiological response that leads to ITP.

In the pathogenesis of primary ITP, autoantibodies against platelet surface antigens such as GPIIb/IIIa and GPIb/IX play major roles. These autoantibodies cause both impaired thrombocyte production and thrombocyte destruction. However, Tcell mediated mechanisms independent from autoantibodies may also be involved (5). The presence of auto-reactive $\mathrm{T}$ cell clones against GPIIb/IIIa epitopes in patients with ITP were shown by Kuwana et al. (19). Other studies have also shown the presence of cytotoxic $\mathrm{T}$ cells against autologous thrombocytes. In addition, an imbalanced Th1/Th2 ratio, increase of oliclonal T cells, Th17 cells and IL17 levels are the other evidence for T-cell mediated mechanisms (20-23). A reduction in the numbers and impairment of the functions of regulatory $T$ cells were also demonstrated $(24,25)$.

All patients included in our study were living in different cities where a Mediterranean climate is seen. This is important because it was shown in various studies that the types and distribution of atmospheric pollen grains vary according to the location and climate, and when the seasons were considered, atmospheric pollen grains were detected most intensively in the spring between March and June (26-28). It is likely that atmospheric pollens reaching maximum levels in the spring (e.g. Platanus, Pinus, and Gramineae) in areas where the Mediterranean climate is observed consistently trigger the immune system. In other words, as the number of allergens like atmospheric pollens entering the human body increases, the immune system increases the production of $B$ cells and antibodies. At this moment, it is possible for B cells to begin designating platelets for destruction. However, there have not been enough studies in the literature showing the relationship of ITP with pollens, other allergens or with atopy. In contrast, several clinical studies have reported the co-incidence of autoimmune and allergic diseases recently, and there is an increasing interest in the relationship between autoimmune and allergic diseases (29). Immune dysregulation secondary to an infectious agent or excessive exposure to a cross-reactive inciting antigen that promotes Th1 response leading to progressive inflammation and autoimmunity is the generally accepted model in the pathogenesis of autoimmune diseases (29). In mutually exclusive patient populations, Th1-type autoimmune disorders and Th2-type mediated allergic disorders would occur and this was predicted by the reciprocal counter-regulation of Th1 and Th2 cells (30). Other lymphocyte subtypes such as Th17 cells, soluble factors such as IL-9 and regulatory T cells were also identified recently as a common link between autoimmunity and atopy (29,31-34). Since ITP is an autoimmune disorder and T-cell abnormalities including Th1, Th2,
Th17 and regulatory T cells play a role in its pathogenesis, the excessive exposure to the increasing number of atmospheric pollens reaching maximum levels in spring may trigger autoantibody formation against platelets, especially in genetically predisposed and maybe in atopic individuals who have a dysregulated immune system.

The limitations of the study include the lack of medical history and/or signs and symptoms of atopy and related laboratory results of the patient cohort.

In conclusion, this study showed that adults with ITP are mostly diagnosed in the spring in areas where a Mediterranean climate is seen. It was also found that the corticosteroid-resistant and chronic ITP patients are mostly diagnosed in the spring. The reason for more patients being diagnosed in the spring may be due to the existence of atmospheric pollens reaching maximum levels in the spring in these areas. Several clinical reports address the relations of allergens with autoimmune diseases, and since ITP is an autoimmune disorder, excessive exposure to the increasing number of atmospheric pollens reaching maximum levels in the spring may trigger autoantibody formation against platelets in patients with a dysregulated immune system. Further research is needed to investigate the roles of allergens and atopy in the pathogenesis of ITP.

Ethics Committee Approval: Ethics committee approval was received for this study from the ethics committee of Mersin University Faculty of Medicine.

Informed Consent: Written informed consent was obtained from patients who participated in this study.

Peer-review: Externally peer-reviewed.

Author contributions: Concept - A.T., B.B.; Design - A.T., B.B.; Supervision - A.T., M.A.S.; Resource - A.T., N.T., M.C., O.S., E.G., K.A., O.K.Y.; Materials - A.T., M.C., K.A., O.K.Y.; Data Collection \&/or Processing - A.T., B.B., M.C., K.A., O.K.Y., G.S.; Analysis \&/ or Interpretation - A.T., M.A.S.; Literature Search - A.T.; Writing A.T.; Critical Reviews - A.T., M.A.S.

Conflict of Interest: No conflict of interest was declared by the authors.

Financial Disclosure: The authors declared that this study has received no financial support.

\section{REFERENCES}

1. Frederiksen H, Schmidt K. The incidence of idiopathic thrombocytopenic purpura in adults increases with age. Blood 1999;94:909-13.

2. Neylon AJ, Saunders PWG, Howard MR, Proctor SJ, Taylor PR; Northern Region Haematology Group. Clinically significant newly presenting autoimmune thrombocytopenic purpura in adults: a prospective study of a population-based cohort of 245 patients. Br J Haematol 2003;122:966-74. [CrossRef] 
3. Schoonen WM, Kucera G, Coalson J, Li L, Rutstein M, Mowat $\mathrm{F}$, et al. Epidemiology of immune thrombocytopenic purpura in the general practice research database. Br J Haematol 2009;145:235-44. [CrossRef]

4. Kurata Y, Fujimura K, Kuwana M, Tomiyama Y, Murata M. Epidemiology of primary immune thrombocytopenia in children and adults in Japan: a population-based study and literature review. Int J Hematol 2011;93:329-35. [CrossRef]

5. Kashiwagi H, Tomiyama Y. Pathophysiology and management of primary immune thrombocytopenia. Int $J$ Hematol 2013;98:24-33. [CrossRef]

6. Neunert C, Lim W, Crowther M, Cohen A, Solberg L Jr, Crowther MA; American Society of Hematology. The American Society of Hematology 2011 evidence-based practice guideline for immune thrombocytopenia. Blood 2011;117:4190-207. [CrossRef]

7. Rodeghiero F, Stasi R, Gernsheimer T, Michel M, Provan D, Arnold DM, et al. Standardization of terminology, definitions and outcome criteria in immune thrombocytopenic purpura of adults and children: report from an international working group. Blood 2009;113:2386-93. [CrossRef]

8. Nugent DJ. Childhood immune thrombocytopenic purpura. Blood Rev 2002;16:27-9. [CrossRef]

9. Provan D, Stasi R, Newland AC, Blanchette VS, Bolton-Maggs $\mathrm{P}$, Bussel JB, et al. International consensus report on the investigation and management of primary immune thrombocytopenia. Blood 2010;115:168-86. [CrossRef]

10. Stasi R, Amadori S, Osborn J, Newland AC, Provan D. Long-term outcome of otherwise healthy individuals with incidentally discovered borderline thrombocytopenia. PLoS Med 2006;3. [CrossRef]

11. Zeller B, Rajantie J, Hedlund-Treutiger I, Tedgård U, Wesenberg F, Jonsson OG, et al. Childhood idiopathic thrombocytopenic purpura in the Nordic countries: epidemiology and predictors of chronic disease. Acta Paediatr 2005;94:178-84. [CrossRef]

12. Hafiz MG, Mannan MA, Amin SK, Islam A, Rahman F. Immune thrombocytopenic purpura among the children attending at two teaching hospitals. Bangladesh Med Res Counc Bull 2008;34:94-8.

13. Moulis G, Palmaro A, Montastruc JL, Godeau B, Lapeyre-Mestre M, Sailler L. Epidemiology of incident immune thrombocytopenia: a nationwide population-based study in France. Blood 2014;124:3308-15. [CrossRef]

14. Rand ML, Wright JF. Virus-associated idiopathic thrombocytopenic purpura. Transfus Sci 1998;19:253-9. [CrossRef]

15. Moulis G, Sommet A, Sailler L, Lapeyre-Mestre M, Montastruc JL; French Association Of Regional Pharmacovigilance Centers. Drug-induced immune thrombocytopenia: a descriptive survey in the French PharmacoVigilance database. Platelets 2012;23:490-4. [CrossRef]

16. Garbe E, Andersohn F, Bronder E, Salama A, Klimpel A, Thomae $\mathrm{M}$, et al. Drug-induced immune thrombocytopenia: results from the Berlin Case-Control Surveillance Study. Eur J Clin Pharmacol 2012;68:821-32. [CrossRef]

17. Grimaldi-Bensouda L, Michel M, Aubrun E, Leighton P, Viallard JF, Adoue D, et al; PGRx Immune Thrombocytopenia Study Group. PGRx Immune Thrombocytopenia Study Group. A casecontrol study to assess the risk of immune thrombocytopenia associated with vaccines. Blood 2012;120:4938-44. [CrossRef]
18. Isai A, Durand J, Le Meur S, Hidalgo-Simon A, Kurz X. Autoimmune disorders after immunisation with Influenza A/H1N1 vaccines with and without adjuvant: EudraVigilance data and literature review. Vaccine 2012;30:7123-9. [CrossRef]

19. Kuwana M, Kaburaki J, Ikeda Y. Autoreactive T cells to platelet GPIIb-IIIa in immune thrombocytopenic purpura. Role in production of anti-platelet autoantibody. J Clin Invest 1998;102:1393-402. [CrossRef]

20. Panitsas FP, Theodoropoulou M, Kouraklis A, Karakantza M, Theodorou GL, Zoumbos NC, et al. Adult chronic idiopathic thrombocytopenic purpura (ITP) is the manifestation of a type-1 polarized immune response. Blood 2004;103:2645-7. [CrossRef]

21. Hu Y, Ma DX, Shan NN, Zhu YY, Liu XG, Zhang L, et al. Increased number of Tc17 and correlation with Th17 cells in patients with immune thrombocytopenia. PLoS One 2011;6:e26522. [CrossRef]

22. Stasi R, Del Poeta G, Stipa E, Evangelista ML, Trawinska MM, Cooper N, et al. Response to B-cell depleting therapy with rituximab reverts the abnormalities of T-cell subsets in patients with idiopathic thrombocytopenic purpura. Blood 2007;110:2924-3290. [CrossRef]

23. Olsson B, Andersson PO, Jernas M, Jacobsson S, Carlsson B, Carlsson LM, et al. T-cell-mediated cytotoxicity toward platelets in chronic idiopathic thrombocytopenic purpura. Nat Med 2003;9:1123-4. [CrossRef]

24. Sakakura M, Wada H, Tawara I, Nobori T, Sugiyama T, Sagawa N, et al. Reduced $\mathrm{Cd} 4+\mathrm{Cd} 25+\mathrm{T}$ cells in patients with idiopathic thrombocytopenic purpura. Thromb Res 2007;120:187-93. [CrossRef]

25. Yu J, Heck S, Patel V, Levan J, Yu Y, Bussel JB, et al. Defective circulating CD25 regulatory T cells in patients with chronic immune thrombocytopenic purpura. Blood 2008;112:1325-8. [CrossRef]

26. Rodríguez-de la Cruz D, Sánchez-Reyes E, Dávila-González I, Lorente-Toledano F, Sánchez-Sánchez J. Airborne pollen calendar of Salamanca, Spain, 2000-2007. Allergol Immunopathol (Madr) 2010;38:307-12. [CrossRef]

27. Bicakci A. Seasonal and regional airborne pollen concentration in Turkey. Turkiye Klinikleri J Allergy-Special Topics 2011;4:10-4.

28. Bicakci A, Altunoglu MK, Bilisik A, Celenk S, Canitez Y, Malyer $\mathrm{H}$, et al. Airborne pollen grains of Turkey. Asthma Allergy Immunol 2009;7:11-7.

29. Pedullá M, Fierro V, Papacciuolo V, Alfano R, Ruocco E. Atopy as a risk factor for thyroid autoimmunity in children affected with atopic dermatitis. J Eur Acad Dermatol Venereol 2014;28:1057-60. [CrossRef]

30. Sornasse T, Larenas PV, Davis KA, de Vries JE, Yssel H. Differentiation and stability of T-helper 1 and 2 cells derived from naive human neonatal CD4+ T Cell, analyzed at the single cell level. J Exp Med 1996;184:473-83. [CrossRef]

31. Steinman L. A brief history of $\mathrm{T}(\mathrm{H}) 17$, the first major revision in $\mathrm{T}(\mathrm{H}) 1 / \mathrm{T}(\mathrm{H}) 2$ hypothesis of $\mathrm{T}$ cell-mediated tissue damage. Nat Med 2007;13:139-45. [CrossRef]

32. Nowak EC, Noelle RJ. Interleukin-9 as a T helper type 17 cytokine. Immunology 2010;131:169-73. [CrossRef]

33. Bacchetta R, Gambineri E, Roncarolo MG. Role of regulatory $\mathrm{T}$ cells and FOXP3 in human diseases. J Allergy Clin Immunol 2007;120:227-35. [CrossRef]

34. Shah A. The pathologic and clinical intersection of atopic and autoimmune disease. Curr Allergy Asthma Rep 2012;12:520-9. [CrossRef] 